\title{
POÉTICA ESCATOLÓGICA HETERODOXA DE EDUARDO ANGUITA ${ }^{1}$ UNORTHODOX ESCHATOLOGICAL POETICS OF EDUARDO ANGUITA
}

\author{
Sergio Pizarro Roberts ${ }^{2}$ \\ Universidad de Playa Ancha, Chile \\ sergioto.pizarro@gmail.com
}

\begin{abstract}
Resumen:
El carácter teísta y heterodoxo de la poética escatológica de Eduardo Anguita es una calificación dada en este artículo como resultado de la problematización semántica de la muerte en su obra. En dicho proceso se establecen vínculos comparativos con su antecedente en la poética huidobriana que demuestran el alejamiento de Anguita respecto de su modelo y la consecuente propuesta de una versión heterodoxa original. En la poética anguitana la figura dominante será el oxímoron que vincula su propuesta poética con otras tradiciones espirituales, como el budismo zen y el taoísmo, que contribuyen a modificar la comprensión de las relaciones entre vida y muerte.
\end{abstract}

Palabras claves: Eduardo Anguita, muerte, oxímoron, teísmo, heterodoxo.

\begin{abstract}
:
The theistic and heterodox character of the eschatological poetics of Eduardo Anguita is a qualification given in this article as a result of the semantic problematization of death in his work. In this process, comparative links are established with its antecedent in the poetics of Huidobro that demonstrate the distance of Anguita from its model and the consequent proposal of an original heterodox version. In the poetics of Anguita the dominant figure will be the oxymoron that links his poetic proposal with other spiritual traditions, such as Zen Buddhism and Taoism, which contribute to modify the understanding of the relationships between life and death.
\end{abstract}

Key words: Eduardo Anguita, death, oxymoron, theism, heterodox.

Recibido: 23/5/ 2017

Aceptado 25/7/2017

\footnotetext{
${ }^{1}$ El presente artículo traduce el esfuerzo de ampliar el rango de autores analizados en la tesis defendida en agosto de 2015 para optar al grado de Magíster en Literatura Chilena e Hispanoamericana en la Facultad de Filosofía y Educación de la Pontificia Universidad Católica de Valparaíso, titulada "Poéticas escatológicas heterodoxas en la poesía contemporánea chilena. Variantes de la resignificación de la muerte en la obra de Pablo Neruda, Gabriela Mistral, Pedro Prado, Vicente Huidobro y Nicanor Parra".

${ }^{2}$ Alumno del programa de Doctorado en Literatura Hispanoamericana Contemporánea de la Universidad de Playa Ancha.
} 
En el afán de seguir escarbando en la poesía chilena con el fin de rescatar los elementos que nos permitan componer el cuerpo de una poética escatológica en nuestro país, he recurrido al trabajo del poeta Eduardo Anguita (1914-1992), cuyos textos son generosos para el resultado de dicha investigación ${ }^{3}$. Es recurrente, en la escasa bibliografía crítica que hay en Chile respecto de este autor, la calificación de su obra como poesía intelectual, metafísica y mística. Siguiendo ese vago derrotero, en este trabajo se intenta precisar esa calificación bajo la premisa de una perspectiva escatológica ${ }^{4}$.

Como antecedente necesario debe señalarse que a la muerte de Rubén Darío, en 1916, poetas como Vicente Huidobro (1893-1948) abandonan el estilo modernista-mimético y adoptan un nuevo estilo vanguardista-creacionista, fuertemente influenciado - en la forma- por la tendencia simbolista del poeta francés Stéphane Mallarmé (1842-1898) y -en el fondo- por la tendencia cubista encabezada por el también poeta francés Guillaume Apollinaire (18801918). El hablante modernista, que tiene por ambición representar miméticamente a la naturaleza, es reemplazado por el hablante creacionista que intenta instalar una nueva realidad a través de una novedosa dicción poética; realidad que sólo tendrá existencia factible en el texto poético. El poema "El espejo de agua", de 1916, es la clave que encarna esta nueva dicción en Huidobro.

Además de esta novedad creacionista existe una segunda que no ha sido completamente percibida por la crítica canónica de la obra huidobriana y que radica en la instauración de un sujeto de la enunciación que emite su discurso desde la muerte, lo cual conlleva, por consecuencia, una resignificación escatológica. Con ello, el creacionismo huidobriano amplía sus márgenes de acción y le otorga un nuevo valor semántico a la muerte. Dicho nuevo valor es, a mi juicio, fundamental para comprender la lógica que subyace a todo el iter poético de la obra huidobriana que se torna críptica, ex profeso, especialmente en su fase tardía.

\footnotetext{
${ }^{3}$ En este trabajo he utilizado el texto que reúne las obras completas de Eduardo Anguita recopiladas con el título Anguita poesía entera, de la editorial Universitaria, colección Letras de América - Cormorán, publicada en el año 1971 y las fechas de los poemarios aludidas en esta tesis son las consignadas en dicho texto. Hago presente lo anterior porque en posteriores recopilaciones los textos sufren diversas modificaciones que fueron hechas en vida del autor, por lo que se presume su participación en los cambios y la subyacente intención estética.

${ }^{4}$ Dos excepciones a esta escasez bibliográfica son, en orden de aparición, la monografía crítica del profesor Ismael Gavilán, titulada Pensamiento y creación por el lenguaje. Acercamiento a la obra poética de Eduardo Anguita (2010), y Anguita 20/20 (2012), editado por Braulio Fernández y Marcelo Rioseco, que reúne el trabajo de 20 investigadores, académicos, escritores y poetas sobre la obra de Anguita.
} 
En una apretada síntesis, puedo señalar que toda la etapa modernista de Huidobro y parte de la creacionista (hasta Poemas árticos) nos brinda un sujeto lírico que descubre a la muerte como un lugar de enunciación inaudito, reconociendo en dichas obras iniciales, su incapacidad para emitir el discurso desde allí. Desde Altazor (ya en la plenitud del creacionismo) el sujeto sufre diversas mutaciones hasta su final transfiguración en pequeño Dios, investido como sujeto de enunciación habilitado para emitir su particular teofanía. La figura del palíndromo "eterfinifrete" en el poema "Altazor" es la clave que permite el tránsito de su discurso a través del umbral de la muerte y con ello se estructura una poética escatológica, sin duda, heterodoxa. En la obra poética tardía del poeta (Ver y palpar y El ciudadano del olvido), el hablante-eternauta sufre un proceso irreversible de incomunicación, una falla técnica de sintaxis que impide la reconfiguración semántica del lenguaje, conduciéndolo al hermetismo y finalmente a la nada, en un desasosegado giro agnóstico 5 .

En sus primeras obras, la poética de Eduardo Anguita se aloja técnicamente en la nueva dicción creacionista $\mathrm{y}$, además, acoge la fórmula del sujeto huidobriano en el tratamiento escatológico ${ }^{6}$. A sus 19 años, en 1933, el joven poeta nos ofrece el poema titulado "Destino Arcangélico", como claro ejemplo de la distancia asumida respecto de la poesía modernista dariana y como el primer ejemplo de un texto de carácter teísta en su obra. Rescato los siguientes versos:

Se produce la asunción del tiempo por relojes de egipcio y resolera.

Dios baja al baño por un cañón de viento

con ángeles que sirven de litera.

Una cigüeña de uva su corbata, sus ojos de redoma o de pecera, al oído una mosca perfumada,

\footnotetext{
${ }^{5}$ Mayores antecedentes respecto de la poética escatológica (en todo el íter poético) de la obra huidobriana pueden obtenerse en mi estudio "La teofanía profana en la obra poética de Vicente Huidobro". Revista Chilena de Literatura $\mathrm{N}^{\circ} 95$, Universidad de Chile, Santiago, 2017.

${ }^{6}$ La obra de Anguita acusa el ascendiente indesmentible de la poética huidobriana y es por ello que muchas de las reflexiones que hago con respecto a su poesía adoptan un mecanismo de contraste con la de Huidobro. Debo precisar, en rigor, que dicho ascendiente no se percibe tan solo en lo relativo a la temática de esta investigación sino que abarca aspectos de la obra de Anguita que incluso exceden a su poética. A modo de ejemplo, se puede constar la omnipresencia de Huidobro en todos los prólogos de la Antología de poesía chilena nueva (1935) y en 15 ensayos de los 125 que componen el libro La belleza de pensar, instalándolo como un referente obligatorio tanto para la poética como para la ensayística anguitana.
} 
y un acuario de flores su pollera. [...]

Después, el atletismo de los ángeles, el salto largo y hondo, y Dios en coche, mientras sprinters corren patinando por el muro alambrado de la noche

Gran festival de vientos y regatas que en orientes de otoño se termina, cuando Dios con el chal de su corbata ahogue al cisne emir de la piscina. [...] $(10,11)^{7}$

"Una cigüeña de uva", "una mosca perfumada" y "un acuario de flores" son ejemplos palpables de imágenes creacionistas en las que la naturaleza no se ve reflejada miméticamente sino que es modificada en aras de una nueva realidad creada por el poeta. Se trata, a su vez, de un poema creacionista en su fase escatológica con figuras propias del teísmo cristiano (Dios, ángeles y arcángeles). Ahora bien, si efectivamente nos encontramos ante un poema teísta en el que se reconoce la existencia de Dios y de otras figuras espirituales, el tono paródico en el que se desarrolla el discurso acusa un alejamiento del tratamiento ortodoxo. Un "Dios en coche" o "el atletismo de los ángeles" desacraliza dichas figuras religiosas y les imprime un tenor profano al situarlas en un escenario más teatral que trascendente. Es notorio, en este poema de 1933, el influjo que recibe de los poemarios Altazor y Temblor de cielo, ambos de Huidobro (1931), en lo concerniente al tratamiento herético de la concepción teísta cristiana. Este poema desarrolla una poética teísta aunque heterodoxa que confiere una tímida e inicial resignificación de la muerte. El mismo tono se repite en textos posteriores que aluden a figuras propias del cristianismo, como es el caso de "El poliedro y el mar" y "Liturgia". En esta última obra, por ejemplo, se estructura un texto dramático en el que se parodia la Misa y el Trisagio (himno en honor a la Santísima Trinidad), y se articulan diálogos, como el de Cristo con Vicente Huidobro, o como el de Arlequín y Lucifer en el infierno, que se alejan de la inspiración piadosa que caracteriza al credo y que, en última instancia, podrían considerarse (al menos ciertos fragmentos) como manifestaciones apócrifas de ritos sagrados.

\footnotetext{
${ }^{7}$ Me siento tentado a pensar que ese Dios que con el chal de corbata ahoga al cisne no es sino el arrebato de un Anguita juvenil que metaforiza la muerte de Darío (cisne) en manos de Huidobro (Dios). Quizá un lejano resabio del célebre soneto "La muerte del cisne" (1911), del poeta mejicano Enrique González Martínez.
} 
Un año después, en 1934, se puede comprobar de qué manera la poética tanatológica de Eduardo Anguita se constituye en fiel heredera del creacionismo escatológico huidobriano. Los poemas "Prohibición de respirar", "Resumen del Pasado" y "Recuerdos de Infancia", incluidos en la sección "Tránsito al Fin”, ofrecen, por primera vez en la obra poética de Anguita, la figura de un sujeto de la enunciación que emite su discurso desde la muerte. Dichos textos inauguran la entrada en escena del sujeto escatológico anguitano y los versos iniciales de "Resumen del pasado" son decidores:

Yo soy el muerto, aquel que pisaba sus propios pies, aquel que tuvo vuestro lenguaje y usó vuestras piernas, sin sombra vivo, cubierto de una desolación de ropas blancas.

Aquí hay vuelo sin necesidad de pájaro, perfume sin flor, ser sin vestido.

Yo soy el que soy, el que nunca fui, el que a pasos se movilizaba para probar que vivía, el que cantaba para oírme, el que pulía su sombra cuya profundidad hoy es mi cuerpo sin latido ni entrañas.

El ser, sólo el ser, el que no debe hablar, porque en sí todas las palabras están dichas, y en el silencio nadie pregunta. SONIDO. [...] (15, las cursivas son mías)

Desde el título de la sección (Tránsito al fin) se desprende la inquietud metafísica que embarga al autor de estos poemas. El título sugiere la idea de la vida como un intervalo al que hay que resignarse, una existencia "transitoria" entre dos dimensiones que la circundan. Algo indefinido precede a la existencia y algo, igualmente indefinido, la sucede, y el sujeto anguitano, tal como el huidobriano, está habilitado para cruzar los portales que separan ambas dimensiones. Al estar capacitado el sujeto anguitano para cruzar dichos portales y emitir su discurso desde la muerte, el sujeto huidobriano pierde la exclusividad del proceso autoasignado en su corpus poético. En ambos casos, el discurso de los sujetos debilita y diluye la relación dicotómica entre vida y muerte. El sujeto anguitano está muerto y vivo a la vez, tal como se desprende de mi énfasis en el poema transcrito. Un fenómeno similar le ocurre al sujeto huidobriano en el poema "Canción de la muervida" (incluido en Ver y palpar, 1941), cuando señala: "Mi cabeza por delante es un señor vivo / [Y] por detrás es un señor muerto" 
(475). Y otro tanto ocurre en el poema "Comaruru" (contenido en Ciudadano del olvido, 1941), de cuyos versos destaco:

$[\ldots]$

Y pasará más allá de la muerte

Porque viene de antes de la vida

Una voz milenaria compuesta adentro de sus olas

Una voz que encontramos como la montaña

Una voz más larga que la mirada del moribundo [...] (509)

En base a la lectura comparada de los textos de ambos autores se desprende sin mayor dificultad la similitud escatológica de los dos hablantes y la consecuente resignificación de la muerte que provocan. Sin embargo, a la vez, se percibe el primer alejamiento del sujeto anguitano, con respecto a la obra de Huidobro, al instituirse como "el ser, el que no debe hablar, / porque en sí todas las palabras están dichas”. El sujeto huidobriano, a diferencia del sujeto anguitano (“que no debe hablar"), no se permite callar. Él es precisamente el ícono inaugural de esta posibilidad poética: la de ser una voz emitida desde un lugar de enunciación que es la muerte, y la función de esa voz es, precisamente, pregonar su propio discurso teofánico. El sujeto huidobriano viene a manifestar lo sagrado; a conferirnos lo que Mircea Elíade acuña en el concepto de hierofanía (hieros, sagrado y faneia, manifestar). En su transfiguración a "pequeño dios", el sujeto huidobriano reemplaza a Dios, en cambio, Anguita, en este aspecto, se aleja de la referida aspiración hierofánica. El sujeto anguitano, al emitir su discurso, no pretende manifestarse como ente sagrado ni reemplazar heréticamente el discurso de Dios.

Otra diferencia con Huidobro, y quizá la más importante, radica en que la resignificación de la muerte en Anguita se ofrece a través de la figura del oxímoron conformado por la complementación contradictoria de los conceptos de vida y muerte. Mediante la contraposición de dos términos opuestos, como son la vida y la muerte, se obtiene un tercer factor resultante que deriva necesariamente en una aporía, la cual sólo puede ser resuelta a través del discurso poético. La insuperable dificultad lógica que conlleva hacer concursar en un mismo campo semántico a dos términos opuestos obliga a indagar en el sentido metafórico de esa relación binaria. 
El sujeto huidobriano que emite su discurso desde la muerte enrarece los límites y concibe a la vida como invasora de la muerte. La asimetría resultante de ese discurso hace prevalecer uno de los términos (vida) respecto de su opuesto (muerte), impidiendo la formación del oxímoron. En cambio, el sujeto anguitano, al tenor del poema "Resumen del Pasado", antes transcrito, insiste en ser oximorónicamente un muerto que vive y no, como en Huidobro, un vivo que invade a la muerte. Otro ejemplo lo confiere el poema "Recuerdo de Infancia", también de Anguita, cuyo extracto transcribo:

Paciencia: mañana el difunto será convaleciente y partirá desde su cuerpo hacia la simplicidad de una voz en la tiniebla endurecida. (17)

Una vez más, la poética metafísica chilena de principios del siglo $\mathrm{XX}$ se ve influida por fundamentos del pensamiento oriental. Comprobamos un acercamiento de la poética escatológica de Anguita al principio del Yin y Yang (en virtud del cual los elementos contrarios no se anulan entre sí sino que se complementan), y una explícita comunión con el pensamiento del budismo $\mathrm{Zen}^{8}$.

En el caso del Yin y Yang, la disyuntiva entre dos elementos opuestos no implica necesariamente la sustitución de uno por el otro; la vida no sustituye a la muerte ni viceversa. El principio occidental del dualismo maniqueo que se funda en la lucha eterna entre dos principios opuestos e irreductibles se ve atenuada en la complementariedad que asume la figura oximorónica de la vida y la muerte en Anguita. La similitud entre la poética de Eduardo Anguita y el pensamiento chino se da, por ejemplo en el aforismo del capítulo XXXVII del Tao te King cuando se lee: "El curso es constantemente inactivo, mas nada hay que no haga." (103). El curso (Tao) actúa sobre la base de la inmanencia en virtud de la cual la realidad acontece permanentemente. "[E]l curso de Lao $\mathrm{Zi}$, -nos señala François Jullien en su

\footnotetext{
${ }^{8}$ Anguita apunta en su ensayo "La extrañeza" que: "La sutileza del orientalismo es definir al Ser Supremo como una negación; más bien: como una serie consecutiva de negaciones. [...] Ser y Vacuidad, en las escrituras del Zen, son lo mismo: algo impersonal, incomprensible, inasible, indefinible. Lo que diferenciaría el pensamiento occidental del oriental es que, como acabo de leerlo en un libro de Octavio Paz, mientras nosotros partimos del Ser, las religiones y filosofías orientales parten del No-Ser. (La belleza de pensar, 87, 88).
} 
introducción a la versión española de 1998 del Tao te King-, no es un curso que lleva a, sino el curso por donde" (11) y cuya virtud radica precisamente en su "procesividad" exenta de toda noción de trascendencia. Anguita secunda esta idea al sostener que: "el mundo es una forma vacía y casi inexistente. Es la nada misma adulando al espacio pero sin ninguna realidad trascendente," (57).

El capítulo XXV del Tao te king revela:

Hay algo confuso y perfecto, anterior al nacimiento del cielo y de la tierra.

Silencioso y solitario, absoluto e inmutable, evoluciona por doquier sin desfallecer.

Podemos tenerlo por madre de cuanto hay bajo el cielo.

No conociendo su nombre, le daré el sobrenombre de "curso". [...] (79)

Un tema central del Tao te King es la idea de la inacción (wu wei). El actuar es siempre forzado y las cosas que vienen por sí mismas en el curso (Tao) se ven cargadas o intervenidas por la arbitrariedad de nuestra voluntad. Dicho texto recomienda que la viabilidad de las cosas obre por sí misma, que opere la inmanencia del "curso" y sostiene, al efecto, que una de las formas para no entorpecerlo es ejerciendo el silencio. El decir es una forma de actuar y una manera de intervenir o forzar el "curso". Por eso las formulaciones del Tao te King son breves e intencionadamente contrarias o paradójicas. Lao zi recurre a enunciados que parecen opuestos y que al contradecir ostensiblemente el sentido común, junto con atenuar la carga de su aseveración, abre enigmas que ofrecen la ampliación del horizonte semántico. Reproduzco nuevamente a Anguita cuando señala: “El ser, sólo el ser, el que no debe hablar, / porque en sí todas las palabras están dichas, / y en el silencio nadie pregunta." (15). El sujeto anguitano es un hablante lírico que se ve forzado a callar y con ello se componen figuras oximorónicas como las del hablante que calla o la del muerto que vive, cuya agresión al sentido común occidental abre enigmas que no son sino nuevas puertas a campos semánticos inexplorados.

En concordancia con lo anterior copio la siguiente cita: "[M]i éxtasis consta de dos movimientos, aparentemente opuestos, pero que en realidad integran un solo estado. [...] lo 
grandioso de este sentimiento es la coincidencia que uno lleva a cabo, parado, por decirlo así, desde el otro mundo." (57). Esta es la transcripción literal de la idea central en "Definición y pérdida de la persona", contenida en su prefacio. Este poema, publicado en el año 1940, completa rigurosamente la poética escatológica anguitana. En efecto, en los poemas contenidos en la sección “Tránsito al fin” tuvimos oportunidad de constatar la existencia de un sujeto habilitado para emitir su discurso desde la muerte y pudimos, asimismo, atisbar la posibilidad discursiva del sujeto anguitano que, sin embargo, no profundiza en su dicción escatológica.

En "Definición y pérdida de la persona" el poeta transmite minuciosamente la experiencia extática que implica emitir su discurso escatológico. Para ello, el autor intercala subtítulos que, a la manera de didascalias, presentan el escenario en que esa experiencia mística se desarrolla. El primer subtítulo "La vida se ha retirado" es decidor para ambientarnos en el contexto discursivo. El sujeto anguitano se encuentra en una zona de la realidad en la cual no hay vida, lo que implica, a contrario sensu, posicionarse necesariamente en la muerte o, al menos, en los límites de la realidad. Comienza, de esta manera, un poema largo en el cual el sujeto nos describe detalladamente su posición en una gran casa vacía e iluminada que se ubica espacial y temporalmente en una dimensión indefinida. Invita, a su vez, al lector a sumarse a esta experiencia y a "mirar por los pasillos, por las escaleras" (58), convocando a un mundo de espejos donde presenciamos a "un ser que olvida su cuerpo" y se desdobla. Continúa el relato con figuras oximorónicas donde la confrontación de opuestos revela lo que el autor quiere transmitir a través de los términos simultáneos y copulativos de "definición y pérdida de la persona". Por ejemplo, se describe una letra atemorizante sobre la cabeza del sujeto, algo parecido a una pregunta sin respuesta; se exhibe a ese sujeto como un "volumen sentado, con dos ojos, o dos hoyos", o sea, que por una parte está vivo y tiene ojos y, por otra, es una calavera que detenta las cavidades orbitarias de esos mismos ojos; también vemos a ese mismo sujeto descrito como una columna que representa "el vacío que quiere imitar al ser. Es la nada que fosforece y, hasta cierto punto, ES" (60), provocando en consecuencia, una aporía en la que ese sujeto representa a una nada que, a su vez, es algo, con lo cual queda entrampado en la dificultad lógica de ser y no ser simultáneamente. 
En esta primera sección, se sostiene que, por sobre cualquier otra cosa, lo que hay es la palabra HAY. "Hasta uno entra en la palabra hay", nos dice el hablante, "con una claridad que daría miedo si uno existiera" (58). Aquí nuevamente se nos impone la dificultad lógica de un sujeto que, explícitamente, reconoce que no existe al plantearse a sí mismo la hipótesis condicional de que sí lo hiciera. Se trata de un hablante que se confiesa muerto con lo cual queda automáticamente habilitado en cuanto sujeto escatológico de la enunciación, dándole coherencia al subtítulo de la sección "La vida se ha retirado", en la cual está inserto el verso comentado.

El mecanismo oximorónico, donde el sujeto se define y se pierde en un sistema que escapa a los contornos delimitados de la vida y la muerte, es un proceso que el sujeto anguitano comparte con el lector cuando nos dice: "[U]sted puede mirar por los pasillos, por las escaleras" (58); y he aquí otra importante diferencia con la poética de Huidobro que ayuda a perfilar el novedoso discurso tanatológico de Anguita. Cabe recordar que la experiencia escatológica en la obra poética de Huidobro es exclusiva del sujeto lírico. A duras penas le concede un lugar en dicho proceso al personaje Isolda, en Temblor de cielo, para acompañarlo en el trance mortal. En todo el resto del opus poético Huidobriano, el cruce del umbral de ultratumba, que se inicia en Altazor, mediante la figura del palíndromo, es propia y exclusiva del sujeto lírico que, en su transfiguración, va mutando (pequeño dios, Altazor, eternauta, infinauta y, finalmente, ciudadano del olvido). En la única ocasión en que se dirige al lector (y que solamente ocurre en la referida obra Temblor de cielo), es para denigrarlo. Se refiere a los seres humanos como "niños terrestres", como "salvajes", para excluirlos, en virtud de su evidente incapacidad, de la experiencia metafísica del sujeto lírico. Les espeta: “[n]o es para vosotros el panorama del secreto naciente. ¿Qué sabéis vosotros de los encuentros de la eternidad?" (432). En cambio, el sujeto anguitano no es excluyente; invita y comparte con el lector (con el resto de la humanidad) su experiencia mística. Democratiza el proceso aristocrático y oligárquico de Huidobro. En otras palabras, según Anguita, todo sujeto está capacitado para vivir la experiencia extática de la resignificación de la muerte 9 .

\footnotetext{
${ }^{9}$ Una posible explicación a esta democratización puede obtenerse mediante la contextualización de la obra de Anguita en la llamada generación del `38 en Chile, cuyos integrantes propiciaron la apertura de la literatura a nuevos espacios sociales, provocando un proceso innovador con respecto a la generación vanguardista inmediatamente anterior.
} 
Para facilitar aún más la masificación de dicha experiencia extática, Anguita se vuelve a alejar de Huidobro al facilitar el trance en un lugar más cotidiano, como puede serlo el más íntimo de todos: la casa. Huidobro, en cambio, obliga al sujeto escatológico a ser astronauta o al menos paracaidista. La experiencia trágica del cruce palindrómico en Altazor tiene connotaciones astrales muy alejadas de las posibilidades de cualquier hombre medio. El escenario de Anguita es más sencillo y la experiencia, aunque extática, no obliga al sujeto a desplazarse sino que a vivirla en una casa en la que se nos presentan elementos cotidianos como muebles, sillones, sillas, pasillos, piezas y ventanas, pero con su carga semántica alterada. Por lo tanto, el sujeto escatológico anguitano no necesita ser un eternauta sino un simple ciudadano que, en la "irritante serenidad" de su domicilio, está "sentado" en una silla, tal como lo explicita el segundo subtítulo del poema. Su experiencia, por lo tanto (a diferencia de Huidobro), es extática y estática, a la vez.

Estas conclusiones obligan a un breve paréntesis para considerar las posibles consecuencias que la obra de Anguita pudo haber tenido, 37 años después, en poetas como Juan Luis Martínez, y que ayudan, en su comparación, a comprender la poética escatológica anguitana. Pienso en el tono intimista del poema "La desaparición de una familia" incluido en La nueva novela, cuyo primer párrafo transcribo:
Antes que su hija de 5 años se extraviara entre el comedor y la cocina, él le había advertido: "Esta casa no es grande ni pequeña, pero al menor descuido se borrarán las señales de ruta y de esta vida al fin, habrás perdido toda esperanza". (137)

Se repite la circunstancia hogareña de la casa con los referentes semánticos trastocados. El mecanismo oximorónico de la casa grande y pequeña se amplía en los párrafos siguientes cuando el hablante señala que la casa, además, "no es ancha ni delgada: sólo delgada como un cabello y ancha tal vez como la aurora" (137); "es bajita como el suelo y tan alta o más que el cielo" (137). Y cuando remata que "por las ventanas de esta casa entra el tiempo, por las puertas sale el espacio" (137), el mecanismo oximorónico al que se ve sometida dicha casa distorsiona su carga semántica original. El sujeto de La nueva novela, a diferencia del sujeto anguitano, se encuentra exento de toda experiencia extática y las 
preguntas metafísicas que subyacen a esa obra reciben respuestas epistémicas, propias de una exploración, más intelectual que espiritual, del discurso.

Continuando con el análisis del poema "Definición y Pérdida de la Persona", se constata la incorporación del erotismo en el proceso extático que experimenta el sujeto anguitano. El sexo es un componente relevante destacado en los subtítulos "Voluptuosidad sexual" y "Actos sexuales". Anguita no descarta el éxtasis copulativo como añadidura para intensificar el proceso de resignificación escatológica. Eros y tanatos se combinan en el discurso del sujeto anguitano cuando señala (continuando con la fórmula oximorónica): “[Y] Aquí y Ahora, Allá y Entonces: todo está en mí. / (Amada mía: ¿eso es la muerte?)” (62). La interrogante supone que la formulación semántica de la muerte está permanentemente en curso (en la "procesividad" del Tao) y en dicha resignificación la participación de la amada es clave; ella viene a insinuar la respuesta según se desprende de los siguientes versos:

Que el sexo de la mujer se ahonde hasta el secreto absoluto

Y el sexo del hombre se levante hasta el oro de la quinta dimensión,

Hasta tocar esos bordes de ser o de nada que rodean, con toda fuerza, nuestra vida, nuestra respiración e inseguridad. (64, el énfasis es mío)

Lo que rodea nuestra vida, esa invisibilidad que la circunda, es lo que en el discurso ortodoxo se denomina muerte y el sexo del hombre y de la mujer, unidos, habilitan al sujeto anguitano a tocar los bordes que dividen la vida y la muerte, y vislumbrar el significado oculto de esa división.

La inclusión del erotismo en la estructura oximorónica de Anguita hay que comprenderla, ya no como resabio de la poética escatológica de Huidobro sino como el resultado de otras lecturas. En su ensayo "Manifiesto de Lawrence" (uno de sus autores predilectos en materia sexual) sostiene:

que la perfección de la persona se opera solo en ese intercambio íntimo de varón y mujer. [...]. Con la mujer, el hombre; con el hombre, la mujer: uno con el otro en íntimo contacto conocen su ser separado. [...] la simultaneidad de ser al unísono dos movimientos opuestos, distintos y complementarios del mismo latido del ser. (La belleza de pensar, 96, la cursiva es mía) 
De la reunión de los opuestos (hombre y mujer) surge una tercera entidad, "su ser separado" o el "tercer ser" (que será analizado en el poema "Negocios ardientes"). Una entidad distinta a los dos seres, considerados individualmente, y que la conforman. La experiencia erótica coadyuva a sus integrantes para percibir la conformación de un nuevo campo semántico que resulta de la relación oximorónica entre vida y muerte; les permite “tocar esos bordes de ser o de nada" que los rodean ${ }^{10}$.

En el proceso de búsqueda de su particular significación de la muerte, el sujeto anguitano acusa la concepción de una poética escatológica indudablemente teísta. Al efecto transcribo parte importante del prefacio del poema "Definición y pérdida de la persona" que, además, resume varios de los puntos antes desarrollados:

Este poema comienza como definición, con el reconocimiento que un Dios hace del mundo que ha creado, o que podría haber creado hace mucho tiempo. ¿Qué son la nariz, los ojos, la voluptuosidad, el acto sexual, para ese Dios que ignora el tiempo y el espacio? ¿Cómo traducirle a su lenguaje de eternidad estas formas temporales y con palabras temporales? Difícil trabajo, ingrata tarea: porque de ningún modo alguien que no sea, como yo (el poeta), dios y hombre a la vez, podrá reconocer la verdad y la justeza de estos hilos que he tendido entre dos mundos tan cerrados. Lo intenté en un momento de fuerte éxtasis. Un éxtasis que hizo esfumarse la realidad, en un comienzo, y, luego, que me hizo comprenderla, sentirla, vivirla, con una patencia irresistible. Es el gozo de vivir, por fin, la realidad después de haber morado en el vacío. Al final el poema se plantea como pérdida. Es la libertad de morir y de vagar, por fin, después de haber verdaderamente vivido.

Ambos movimientos podrían ser perpetuos, y nada sino la fragilidad humana habría de impedir que se sucedieran a través de nuestro ser hasta el infinito: Eternidad, tiempo, eternidad, tiempo. Rayado por estos dos túneles alternos, una hermosa zebra es el hombre. El que se atreva, lea mi poema toda la vida, y encarne, con vigor y profundidad crecientes, el símbolo de mi animal. (58) ${ }^{11}$

\footnotetext{
${ }^{10}$ El carácter heterosexual que Anguita imprime a la experiencia extática corre el riesgo, hoy en día, de hacer cuestionable la universalidad de su discurso poético al excluir, del proceso de resignificación escatológica, a todo sujeto cuya orientación sexual no sea precisamente la heterosexual. Sin embargo, esta obra (del año 1940) debe enmarcarse dentro de los márgenes de la modernidad de las vanguardias, con todas las limitaciones teóricas que dicho movimiento experimentó y es preciso neutralizar la mirada para focalizarla en el ejercicio de reformulación semántica.

${ }^{11}$ Es importante resaltar que en la versión del poema "Definición y pérdida de la persona", publicado el año 1988, por la editorial Universitaria, el autor cambia a minúscula la mayúscula que tenía la palabra Dios en la
} 
En cuanto al carácter teísta de la poética escatológica de esta obra corresponden ciertas precisiones. Nótese que el sujeto anguitano se auto califica, en cuanto poeta, como dios y hombre. Conste que es dios con minúscula para contraponerlo a la divinidad con mayúscula que aparece en el mismo texto. Lo anterior es un obvio resabio de la figura del pequeño dios que se transfigura en la obra huidobriana. Sin embargo, en la poética de Anguita, este pequeño dios no reemplaza heréticamente a Dios sino que, todo lo contrario, avala y justifica su existencia. Es más, se manifiesta la necesidad de una interlocución con ese Dios y el hablante reconoce la dificultad lingüística que se produce entre ambos. La precariedad de la interlocución se percibe en la necesidad de la traducción del mensaje cuando se pregunta “¿Cómo traducirle a su lenguaje de eternidad estas formas temporales y con palabras temporales?" Se reconoce, por ende, la existencia de un lenguaje de eternidad cuyo titular legítimo es Dios y le corresponde al poeta traducir el lenguaje temporal al lenguaje de eternidad. Los dos mundos cerrados representados en el prefacio, son la vida y la muerte, y la traducción del poeta son "los hilos" que se tienden entre ambos. "Traducirle el lenguaje temporal a Dios" viene a ser una forma de resignificación escatológica. En otras palabras, la reformulación semántica de la muerte a través del discurso poético del sujeto anguitano no es otra cosa que la intención de traducirle a Dios (a su lenguaje de eternidad) el significado de la muerte con "palabras temporales".

El profesor Gavilán, en una ardua labor de rescate de la teoría poética de Eduardo Anguita, desempolva la revisión que este elabora del concepto creación, y que respalda la tesis teísta de su obra sostenida en este trabajo. Según Gavilán, Anguita y Huidobro convergen en el concepto de creación pero con un matiz que aleja al primero del creacionismo cientificista del segundo. Agrega que, para Anguita, la comprensión metafísica del concepto creación "implica, necesariamente, que la creación se halla vinculada a un trascendentalismo

versión de 1971, en particular, las dos primeras ocasiones en que aparecen en el texto transcrito. A mi juicio se trata de un cambio que altera sustancialmente el acercamiento hermenéutico a la obra. Si es con minúscula, el dios aludido es el mismo sujeto anguitano y si es con mayúscula se refiere a otra entidad distinta a dicho sujeto, esto es, a la divinidad propiamente tal. En efecto, el crítico Ismael Gavilán formula su hipótesis, respecto de este poema, sobre la base del texto con minúscula y, en virtud de esta circunstancia, sostiene que "la temporalidad del lenguaje puede crear ("definir" como dice el texto) un sujeto desde sí mismo a semejanza de un dios" (Pensamiento y creación por el lenguaje. Acercamiento a la obra poética de Eduardo Anguita, 143). Si la lectura se realiza sobre la base de Dios con mayúscula se modifica el horizonte interpretativo, derivando a conclusiones diversas. 
que da cuenta de la idea de Dios creador" (123) y que, por ello, desconfía de la desacralización del ejercicio creativo. Sin embargo, Gavilán, en contra de lo aseverado por Enrique Lihn y Pedro Lastra acerca de "la visión esencialista, espiritualista, [y] finalmente católica" de la escritura de Anguita (en "Lectura de ciertos poemas chilenos", El circo en llamas, 208) advierte agudamente que:

sería un tanto arriesgado aseverar unilateralmente que Anguita es un poeta católico. Tal vez, aquel "catolicismo" sea más heterodoxo de lo que pueda apreciarse a primera vista, pues siempre tendrá que vincularse con las tensiones propias del discurso poético. Sin negar la autenticidad personal de las manifestaciones de fe de Anguita, queda bastante por rastrear acerca de la interpretación que del cristianismo católico efectúa la poesía del autor de Venus en el pudridero. (119)

Coincido con esta aprensión aunque precisaría que la calificación de heterodoxo habría que asignársela más al carácter teísta de su poética que al dudoso catolicismo de la misma por cuanto, en verdad, cabe preguntarse si el Dios a que se refiere el prefacio es efectivamente el Dios cristiano o se está ante una figura teológica nueva ${ }^{12}$.

Según el Nuevo Diccionario de Teología "para los cristianos [...] la muerte representa la transición entre la forma de vida física que se extingue con ella y el comienzo de una nueva forma de vida" (655). En la misma línea, y según la interpretación canónica del Nuevo Testamento, no se considera a la muerte "como un fenómeno biológico, sino teológico, [ya que] siempre que la persona humana rompe su relación con Dios, [...] abandona la raíz de su vida y cae en la muerte" (658).

La concepción cristiana vino, por consecuencia, a resignificar semánticamente a la muerte. Modificó la concepción antropológica (muerte como sinónimo de destrucción física)

\footnotetext{
${ }^{12}$ Respalda esta posición el crítico Juan Gabriel Araya cuando asevera que: "Una honda religiosidad vertebra el significado poético [de la obra de Anguita], la cual proviene de un rigor mental y no de arranques místicos tradicionales u ocasionales posturas religiosas cristianas" (150). La profesora María Luisa Martínez, en cambio, en su análisis del poema "Venus en el pudridero", no transmite la misma seguridad en su fórmula disyuntiva: "[E]l final del poema plasma la concepción católica de Anguita, su función sacerdotal o su intención de abordar la creación poética desde el ámbito religioso." (Anguita 20/20, 20). Finalmente, el profesor Diego Honorato, nos ofrece una lectura Cristo-céntrica del poema "Definición y pérdida de la persona" (Anguita 20/20, pp. 58-73), y la poeta Soledad Fariña, por su parte, permite que en su reflexión sobre el vacío, en el poema "El poliedro y el mar", cohabite una perspectiva budista del texto con una visión cristiana del mismo (Anguita 20/20, pp. 86-94). Todo lo cual nos permite constatar, frente a estas posturas académicas, la dificultad hermenéutica que plantea el trabajo de Anguita, visto desde una perspectiva escatológica.
} 
y la posterior concepción helénica (muerte como liberación del alma, según Platón). Para la concepción cristiana, la relación binaria de vida y muerte encuentra su punto de oposición semántica, no en el momento de la extinción física del cuerpo y su posterior degradación, sino que en el momento en que se produce el quiebre con Dios. De esta manera quien, en vida, se encuentra alejado de Dios está realmente muerto y, viceversa, quien ha muerto en la gloria de Dios estará vivo eternamente.

Para el cristianismo "la muerte representa el comienzo de una nueva vida". De este modo, la relación binaria de vida y muerte contiene la apariencia de un oxímoron ya que, bajo el supuesto cristiano, la muerte pierde toda su carga semántica vinculada a la destrucción, a la nada y al vacío para constituirse como una supra vida, con una potencia que sobrepasa la carga vivífica de la vida terrenal. En la poética escatológica de Anguita, en cambio, no se sobrepone un término por sobre su opuesto; la vida no se sobrepone a la muerte y se mantiene una distancia prudente entre los opuestos que estabiliza el equilibrio del oxímoron.

Por su parte, en el poema "Definición y pérdida de la persona" no se menciona a Cristo, a la Virgen, u otras figuras cristianas. El texto sólo contiene referencias a Dios, en cuanto divinidad no vinculada a un credo específico. Asimismo, la incorporación del erotismo en el proceso extático que experimenta el sujeto anguitano se aleja del fundamento espiritual del credo cristiano. El sexo, el cuerpo, la carne y el pecado son parte de una cadena de términos que conforman una nomenclatura que no aporta para la santificación del espíritu sino que todo lo contrario, la degrada. Por lo tanto, la propuesta escatológica de la poética anguitana se aleja de la doctrina tradicional u ortodoxia religiosa de Chile, que ha sido históricamente el credo de la Iglesia Católica, y sustenta una poética heterodoxa, aunque teísta.

Estas conclusiones conllevan necesariamente la pregunta de rigor acerca de cuál sería, en definitiva, la nueva formulación de la muerte que ofrece la poesía de Anguita al separarse de la tradicional cristiana. Estimo que su poesía no contempla respuestas a esta interrogante, o mejor dicho, que su respuesta consiste precisamente en dejar abierta la pregunta, lo que confiere consecuencia a su discurso. En efecto, si la experiencia extática del sujeto anguitano se sostiene sobre la figura del oxímoron, la relación binaria entre los elementos opuestos de la vida y la muerte no puede disolverse. La polarización conforma un campo magnético en el que ninguno de los dos polos (vida o muerte) tiene preponderancia y sus componentes se 
neutralizan. Si volvemos al plano semántico, comprobamos que la figura del oxímoron, que contrapone dos términos opuestos, como son la vida y la muerte, obteniendo un tercer factor resultante, deriva necesariamente en una aporía y que sólo se resuelve a través del discurso poético. Tal como señalé al inicio de este trabajo, la insuperable dificultad lógica que conlleva hacer concursar en un mismo campo semántico a dos términos opuestos obliga a indagar en el sentido metafórico de esa relación binaria.

"Definición y pérdida de la persona" termina precisamente con interrogantes sin respuesta cuando en el último subtítulo de la obra "[E]l poeta se pone de pie y reza: "Dios mío, ¿dónde es el dónde? ¿Qué pregunta soy?” (64). El sujeto anguitano pierde visibilidad conceptual y en el último verso piensa: "Ahora va a ser tarde: es tarde, brumas mías"13.

El poema "El verdadero rostro", de 1941, complementa el anteriormente analizado al señalar:

Y vi atrás, el verdadero Rostro sin delante ni detrás.

Era el rostro sin cara, vacío, [...]

Sin palpitación, sin vida, $[\ldots]$

Detrás de la persona hay un rostro hecho de orden, ¿Se puede ser sin ser algo? Como la presencia que trasciende [...] (65)

Nuevamente el sujeto anguitano profiere preguntas insolubles en las que contrapone el ser y el no ser, la nada con el todo, la vida y la muerte para debilitar, con dicha oposición binaria, la acepción consensuada de los términos individualmente considerados. Dicha debilidad semántica redunda en una reformulación del concepto y, en el caso de la muerte, en una incipiente resignificación con la vaga expresión de "una presencia que trasciende". No estamos frente a la retórica de un hermetismo fácil sino en presencia de una posible solución poética ante la encrucijada aporética que deriva de la yuxtaposición semántica de vida y muerte.

Lo anterior se confirma en otro poema titulado "Negocios ardientes", del año 1939, cuyo tercer subtítulo reza: "Terrible imposibilidad de lograr la comprensión vital del abismo

\footnotetext{
${ }^{13}$ Cristián Warnken, en su ensayo "Eduardo Anguita viene preguntando", discurre: "Anguita viene auroleado por un preguntar activo [...] [S] us preguntas ya no tienen respuesta, porque la metafísica occidental desde y hacia donde él pregunta, ya no existe [...] Anguita está manchado de las preguntas que apuntan al corazón de lo indecible [...] el preguntar en Anguita era el éxtasis de un místico del Logos [...] Anguita salvó a las preguntas de la vieja filosofía occidental de la muerte" (Anguita 20/20, 211, 212 y 215).
} 
por culpa del pensamiento dual y, sobre todo, por el tiempo que sintetiza nuestro terror al Tercer Ser." (55). Dicho pensamiento dual (aplicable a las nociones de vida y muerte) configura un abismo imposible de comprender y que redunda en un nuevo campo semántico, un “Tercer Ser". Con ello, la novedad poética de Anguita, más que ofrecer una reformulación escatológica específica, abre un intersticio dentro de la oposición antagónica entre vida y muerte, que da como resultado dicho nuevo campo semántico, desde el cual el sujeto anguitano emite su discurso poético, convirtiéndose en el "náufrago de [su] propia nueva resurrección" (57).

En el largo poema "Venus en el pudridero", de 1960, el sujeto anguitano continúa incursionando en la interrogante planteada en las obras anteriores:

Oh vida, en qué te diferencias de la muerte, me pregunto.

Como el entusiasmo y el desánimo, arrastráis igual substancia.

Como (sic) sé cuándo amanece y cuándo atardece.

No tengo mi ayer. No tengo mi mañana. Juzgo que es mediodía.

$[\ldots]$

Una luz ya apagada vale lo que otra aún no encendida,

El camino es el mismo de subida que de bajada.

Daréis lo no venido por pasado.

[...]

Vivir, morir, ¿qué color, qué movimiento os distingue?

$[\ldots]$

¡Vida, vida! Sin duda, eres diferente de la muerte; pero ahora, ¡ay, no puedo distinguirte! $(85,86)$

El sujeto no sólo persiste en la pregunta sino que, a modo de respuesta, reconoce el riesgo que conlleva definir sobre la resbalosa superficie de las acepciones. Mantiene el equilibrio de la relación dicotómica entre los conceptos de vida y muerte que propende, en consecuencia, a la formación de un nuevo campo semántico, en el que no necesariamente se confiere primacía a un término por sobre su opuesto ${ }^{14}$.

Existe un poema del año 1955, titulado "Sonetos del extranjero" que da un paso más allá en las interrogantes sin respuesta. Cito los siguientes fragmentos:

\footnotetext{
${ }^{14}$ Una opinión distinta contiene el artículo "Venus en el pudridero: la utopía poética de Eduardo Anguita", de la profesora María Luisa Martínez, al otorgarle a la vida una fuerza superior a la muerte en su relación antinómica. Al efecto señala: "La palabra es, de esta manera, afirmación de una vida que contiene a la muerte, como dos polos inseparables, pero que expulsa a esta última, la desafía y la resiste.” (Anguita 20/20, 25).
} 
Sólo sé que quedé sin nacimiento, Arrojado al dominio del momento, Sin edad, sin pañal, sin sepultura.

$[\ldots]$

México, Muerte, Amante: nuevamente

Nazco con un dolor ya soportado,

De repente me nace otro pasado

Y me nace otra madre de repente.

$[\ldots]$

Por hallarte, de madre en madre he ido

Naciendo y desnaciéndome y matando

Cuanta madre pequeña me ha querido. $(13,14$, la cursiva es mía)

En el particular recuerdo de su madre, el sujeto anguitano insiste en la resignificación escatológica sostenida sobre la base de la relación oximorónica entre vida y muerte, y de cuya relación antagónica surge la posibilidad de un nuevo campo semántico. La muerte es reformulada mediante el intersticio que se interpone entre los verbos nacer y morir al intercalar un tercer verbo intermedio: el neologismo místico "desnacer". Se podría aseverar, sin temeridad, que desnacer no significa dejar de vivir y tampoco implica morir ni matar. El sujeto anguitano, en su calidad de "náufrago de su propia nueva resurrección”, al "desnacer”, se permite habitar el "Tercer Ser” y ante la pregunta aporética “¿se puede ser sin ser algo?” dicho sujeto responde poéticamente: sí, desnaciéndote. ${ }^{15}$

En este punto de la reflexión se puede aseverar que la poética escatológica de Anguita, más que una inquietud religiosa, parece acusar una afrenta al lenguaje. Efectivamente en su obra existe una inquietud metafísica, pero al subordinar dicha inquietud a soluciones lingüísticas, en particular al uso de la figura contradictoria del oxímoron, se relativiza la intensidad espiritual que subyace al discurso poético. El sujeto anguitano utiliza categorías del pensamiento oriental, -especialmente las que propugnan la disolución de la individualidad después de la muerte, como el budismo zen o el taoísmo-, no para ceñirse religiosamente a ellas, sino para tergiversar la estructura maniquea del discurso occidental. Puede incluso

\footnotetext{
${ }^{15}$ La tesis sustentada en esta investigación indaga en la resignificación de la muerte en la poética de Eduardo Anguita y el resultado de esta apertura semántica trae como consecuencia múltiples interpretaciones esotéricas que sobrepasan los límites de este trabajo. Sólo a modo de ejemplo, se pueden hacer conexiones apócrifas de la Santísima Trinidad con el Tercer Ser (Ter-Cer-Ser; "Ter" es un adverbio latino que significa "tres veces", o sea tres veces dos seres) y el mismo texto "Sonetos del extranjero" termina con los enigmáticos versos: "iNueve, da a luz al Tres que te ha creado! / ¡Oh Jaula numeral, oh transparencia, / Rosa, deja volar de ti la esencia / Y permite que el Tres regrese al Uno!" (14).
} 
aseverarse que la poética de Anguita asume una fijación esteticista, estrictamente lingüística, que ofrece otra mirada de la realidad, no para modificarla sino para testimoniar su evanescencia. Como consecuencia de lo anterior, su obra refleja un distanciamiento de la inspiración moderna de las vanguardias y confirma su posición en trincheras que son más propias de una vanguardia tardía. "Sí, el arte es vida, no la vida, porque ésta no es realmente vida, sino apariencia de ella. La poesía actual, como vida, deslinda en los pesados límites de flores con la muerte", es lo que redacta Eduardo Anguita, a modo de conclusión, en el segundo prólogo de la clásica Antología de poesía chilena nueva, de 1935 (29) ${ }^{16}$.

En definitiva, y confinando la fase agnóstica en un paréntesis vital del autor, se puede sostener que la poética escatológica de Eduardo Anguita adopta una acepción teísta en cuanto asume una realidad en la que coexiste la dualidad de un ser creador (Dios) y un ser creado (hombre/mujer). Esta concepción teísta escapa a la ortodoxia del credo cristiano y confiere una resignificación heterodoxa de la muerte a través de la figura oximorónica en que la relación dialéctica entre vida y muerte deviene en un tercer campo semántico no del todo explicitado. El campo semántico resultante es un lugar de enunciación que habilita al sujeto anguitano para emitir su discurso desde allí, y que permite calificarlo como un sujeto de la enunciación escatológico al estar capacitado por el lenguaje para cruzar los umbrales que separan la vida de la muerte.

Nosotros apuntábamos a la Religión. No a la nuestra tradicional ni a ninguna otra ya predicada, sino a la que cada uno debería crear según ese poder otorgador de sentido que posee la conciencia (Hegel) y que el poeta, más que nadie, cree el único patrón y la única medida de la realidad.

(La belleza de pensar, Anguita).

\footnotetext{
${ }^{16}$ Con todo, el discurso poético de Anguita, hasta aquí, es coherente, en su complejo tratamiento de la resignificación de la muerte, al configurar una poética escatológica teísta aunque heterodoxa. Sin embargo, el poema "La Muerte es la suma de muchas vidas" (1940, el mismo anno mirabilis del poema "Definición y pérdida de la persona"), al designificar a la muerte con la nada, se constituye como una verdadera excepción o paréntesis en el opus escatológico de Eduardo Anguita. El teísmo heterodoxo de la poética de Anguita, en lo que va de esta investigación, permite una reformulación semántica de la muerte, en cambio, el criterio agnóstico que subyace a este poema rechaza toda consideración metafísica y, por ende, la posibilidad poética de una resignificación escatológica.
} 


\section{Bibliografía}

Anguita, Eduardo. Anguita poesía entera. Santiago: Editorial Universitaria, 1971. Impreso.

---------.La belleza de pensar. Valparaíso, Chile: Editorial UV de la Universidad de Valparaíso, 2013. Impreso.

Anguita, Eduardo y Teitelboim, Volodia. Antología de poesía chilena nueva (1935). Santiago: segunda edición, Editorial LOM, 2001.

Araya, Juan Gabriel. "Eduardo Anguita y su poema La visita". Revista Chilena de Literatura 18 (1981): 149-158. Impreso.

Fernández, Braulio y Rioseco, Marcelo. Anguita 20/20. Santiago: Editorial Universitaria, 2012. Impreso.

Gavilán, Ismael. Pensamiento y creación por el lenguaje. Acercamiento a la obra poética de Eduardo Anguita. Concepción: Ediciones Escaparate-Universidad Viña del Mar, 2010. Impreso.

Huidobro, Vicente. Obras completas. Santiago: Zig-Zag editores, 1964.Impreso.

Lihn, Enrique. El circo en llamas. Santiago: LOM ediciones, 1997. Impreso.

Martínez, Juan Luis. La nueva novela. Santiago: ediciones Archivo, 1985. Impreso.

Tamayo, Juan José. Nuevo diccionario de Teología. Madrid: Editorial Trotta, 2005. Impreso.

Zi, Lao. Tao te King. Madrid: Ediciones Siruela, 2007. Impreso. 